\title{
DETECTION OF ASPERGILLUS SPP. IN BIOLOGICAL SAMPLES BY REAL-TIME PCR
}

\author{
Radka Bolehovska ${ }^{a *}$, Lenka Pliskova ${ }^{\mathrm{a}}$, Vladimir Buchta ${ }^{\mathrm{b}, \mathrm{d}}$, Jaroslav Cerman ${ }^{\mathrm{c}}$, Petr Hamal \\ a Department of Clinical Biochemistry and Diagnostics, Faculty of Medicine and University Hospital, Charles University, \\ 50005 Hradec Kralove, Czech Republic \\ ${ }^{b}$ Department of Clinical Microbiology, Faculty of Medicine and University Hospital, Charles University, 50005 Hradec \\ Kralove \\ c Department of Clinical Hematology, Faculty of Medicine and University Hospital, Charles University, 50005 Hradec \\ Kralove \\ ${ }^{d}$ Department of Biological and Medical Sciences, Faculty of Pharmacy, Charles University, 50005 Hradec Kralove \\ e Department of Microbiology, Faculty of Medicine and Dentistry, Palacky University, 77515 Olomouc \\ * Corresponding author
}

fax: +420495832003

e-mail:bolehrad@fnhk.cz

Received: April 12, 2006; Accepded: September 10, 2006

Key words: DNA detection/Real-time PCR/Mycoses/Aspergillus/Laboratory diagnosis/Invasive aspergillosis

Background: Recently, the proportion of invasive infections caused by the filamentous fungi of the Aspergillus genus are growing in immunocompromised persons particularly in transplant recipients and neutropenic patients. Unfortunately, laboratory diagnostics of invasive aspergillosis remains extremely difficult, mainly with regard to the sensitivity of the methods and to the correct interpretation of the results in particular.

Aim: The aim of this work was to design a standard and reproducible Aspergillus DNA detection method and its validation. The second aim was to practically use this method for diagnosis of Aspergillus DNA in various samples in patients.

Method: Real-time PCR with two hybridization probes. Amplification and on-line quantification was carried out on a LightCycler ${ }^{\circledR} 1.5$ Instrument.

Results: Specificity of the reaction was tested for A. fumigatus, A. flavus, A. niger and A. terreus, and its sensitivity was determined at 5 copies per $\mathrm{ml}$. The reproducibility of the results was comparable to other methods, reported in the literature.

Applicability of the real-time PCR was assessed for detection of Aspergillus DNA in 354 various clinical samples taken from 179 patients at risk of invasive aspergillosis over the period of 33 months. Of 354 samples 103 (29.10\%) taken from 65 patients $(36.31 \%)$ were evaluated as positive. Over one year, the percentage of positive samples was mostly about $30 \%$ or less per month.

Conclusions: Our results demonstrate the high sensitivity, specificity and reproducibility of this technique, and its usefulness for rapid laboratory diagnosis of invasive aspergillosis.

Currently, the proportion of invasive infections caused by the filamentous fungi of the genus Aspergillus is growing in immunocompromised persons, particularly in transplant recipients and neutropenic patients. Invasive aspergillosis (IA) usually develops after inhaling the air-borne conidia.

In such patients, the bronchopulmonary form of IA occurs most frequently, with the infection being capable of further dissemination from the primarily affected lower respiratory tract. This fungal disease is very devastating, mainly due to the strong angioinvasiveness of the Aspergillus species. A. fumigatus is the dominant etiological agent, followed by A. flavus and A. terreus. Therefore, it is not surprising that IA mortality in immunocompromised patients commonly exceeds $50 \%$ despite antifungal therapy ${ }^{1}$.
It is widely accepted that successful therapy of IA closely depends on early detection of the fungus followed by an aggressive specific treatment. This mainly includes treatment by high doses of amphotericin B or its lipid formulations, and most recently by a new triazole voriconazole and echinocandin derivatives ${ }^{2-5}$. Unfortunately, laboratory diagnostics of IA remains extremely difficult, mainly due to the sensitivity of the methods and to the correct interpretation of the results.

Rapid laboratory diagnostics of IA has recently been based, above all, on immunological detection of the Aspergillus antigen (galactomannan, beta-glucan) and/or nucleic acid in the blood or other body fluid samples, especially from the respiratory tract ${ }^{6}$.

We have optimized previously published quantitative PCR assay ${ }^{7}$ for detection of DNA from medically most 
relevant Aspergillus species. Optimized real-time PCR (rt-PCR) was then used for detection of Aspergillus DNA in various samples.

\section{MATERIALS AND METHODS}

Characteristics of the patients. 354 various clinical materials including 210 of plasma or serum $(59.32 \%)$, 125 lung samples $(35.31 \%$, i.e. 70 bronchoalveolar lavage fluids (BAL), 45 sputum, 2 aspirate fluid, 6 thoracic puncture fluid, 1 bronchial tissue and 1 lung biopsy) and 19 other clinical materials $(5.37 \%$, i.e. 9 cerebrospinal fluids (CSF), 1 liver tissue, 1 pericardial exudation etc.)

All clinical samples were obtained from 179 patients at risk of aspergillosis (112 men, 67 women). 92 suffered from different oncological diseases, 34 from respiratory tract diseases, 13 from hematological diseases and 40 from other diseases. Mostly, patients suffering hematological malignancies were sampled. The average age of patients was 53 years and the age range was $4-84$ years.

Clinical samples were taken from the patients over a period of 33 months, from April 2003 to December 2005.

DNA isolation. Plasma or serum, BAL fluid or other fluid samples of $300 \mu \mathrm{l}$ to $1 \mathrm{ml}$ in volume were centrifuged at $16,060 \mathrm{~g}$. Then, the pellets were used for DNA extraction with the phenol-chloroform technique as described earlier ${ }^{8}$. The isolated DNA was stored at $4^{\circ} \mathrm{C}$ over $48-72$ hrs or at $-70{ }^{\circ} \mathrm{C}$ in the cases where longer storage was necessary.

All samples were analyzed in duplicate.

Rt-PCR. Aspergillus fumigatus mitochondrial transfer RNA-Thr, -Glu, -Val, -Met and ribosomal RNA gene (GenBank L37095) was used for amplification as published earlier, with the amplicon size $91 \mathrm{bp}^{7}$. Rt-PCR for Aspergillus DNA detection was modified in our laboratory. Amplification and on-line quantification was carried out on a LightCycler ${ }^{\circledR} 1.5$ Instrument (Roche Diagnostics, Mannheim, Germany). Two hybridization probes were used (TIB-MOLBIOL, Berlin, Germany): 24-mer 5'-CTGTTAGTGCGGGAGTTCAAAXTCT-3', where $\mathrm{X}$ is the internal labeling of $\mathrm{T}$ by the LightCycler (LC) Red 640, and 28-mer 5'-CTGAGCTAATTTCTT TCAACCCAAGGGA-3', labeled at the 3'end by fluorescein isothiocyanate. The LC Red 640 hybridization probe also served as the sense primer for template amplification. The 22-mer antisense primer sequence was 5'AACACCTGACCTTTCGCGTGTA-3' (Generi Biotech, Hradec Králové, Czech Republic).

The PCR mixture of $10 \mu \mathrm{l}$ in volume consisted of $1 \times$ LightCycler Fast-Start DNA Master HybProbe (Roche Diagnostics, Mannheim, Germany), $3 \mathrm{mmol} / 1 \mathrm{MgCl}_{2}$, 0.2 U UNG (uracil-DNA-glycosylase, Roche Diagnostics, Mannheim, Germany), the respective primer in the concentration of $0.8 \mu \mathrm{mol} / 1$, the fluorescein isothiocyanatelabeled probe in the concentration of $0.4 \mu \mathrm{mol} / 1$, and $5 \mu \mathrm{l}$ of the template. The temperature profile of the PCR reaction was as follows: $50{ }^{\circ} \mathrm{C}$ for 5 min for UNG activation, $95^{\circ} \mathrm{C}$ for 10 min as the initial denaturation, and 55 cycles with the temperatures of $95^{\circ} \mathrm{C}$ for $5 \mathrm{~s}, 60^{\circ} \mathrm{C}$ for $10 \mathrm{~s}$, and $72{ }^{\circ} \mathrm{C}$ for $15 \mathrm{~s}$. Sample fluorescence was measured in each cycle at the end of the annealing.

In order to verify the absence of DNA polymerase inhibitors, end-point PCR followed by agarose gel electrophoresis was carried out. Part of the gene for the human beta-globin was used as an internal control of the amplification.

\section{RESULTS}

Repeatability (accuracy in a series) of the optimized rt-PCR was determined 10 times using two samples of different concentration of Aspergillus DNA and the coefficient of variation was $\leq 1.28 \%$. Reproducibility (accuracy between days) was determined by testing two samples of different concentration of Aspergillus DNA measured in duplicate in five independent runs, the coefficient of variation was $\leq 2.43 \%$.

The real-time PCR reaction was positive with examined strains A. fumigatus AF13, A. flavus ATCC 36607, A. niger ATCC 10535, A. terreus DSM 826 and PCR sensitivity was found to be at 5 copies of Aspergillus DNA per $\mathrm{mL}$.

Among the 354 biological samples from 179 individuals Aspergillus DNA was detected using the rt-PCR in 103 samples (29.10\%). 247 samples were negative $(69.77 \%)$, and the presence of the reaction inhibitors was found in 4 cases $(1.13 \%)$. Of the overall number of 179 patients, 106 were examined once (59.22\%), 33 twice (18.44 $\%), 17$ three times ( $9.50 \%), 10$ four times (5.59\%), 4 five times $(2.23 \%)$ and 4 six times $(2.23 \%), 1$ seven times $(0.56 \%), 2$ eight times ( $1.12 \%), 1$ ten times $(0.56 \%)$ and 1 eleven times $(0.56 \%)$. Positive results were obtained with samples from 65 patients ( $36.31 \%$; i.e. 43 men and 22 women). Aspergillus DNA was detected in 44 patients only once (67.69\%), in 10 patients twice ( $15.38 \%$ ), in 8 patients three times $(12.31 \%)$ and in 3 patients five times. Among 210 blood samples, 54 were positive $(25.71 \%$ ), in 125 lung samples were positive $44(35.20 \%)$ and the other samples (19) were positive in 5 cases $(26.32 \%)$. In the positive samples, the amount of the Aspergillus DNA was usually up to 50 to 100 copies per $\mathrm{mL}$. In the group of 88 patients with oncological diagnosis in 32 cases positive results were found ( $36.36 \%$ ), among 31 patients with lung disease 13 were positive ( $41.94 \%$ ), among 13 patients with haematological diagnosis 4 were positive $(30.77 \%)$ and in the group of 47 patients with other diagnoses 16 patients were positive (34.04\%).

\section{DISCUSSION}

Several studies have demonstrated recently that Aspergillus DNA can be detected successfully in various samples by different PCR-assays ${ }^{7,9-14}$. We have evaluated the specificity of determination, sensitivity, repeability 
and reproducibility of an rt-PCR published earlier ${ }^{7}$ and optimized by ourselves. The specificity of determination and high sensitivity found was comparable to commonly used nested PCR-assay ${ }^{10}$. Repeatability and reproducibility of the PCR-assay optimized by us was sufficient, and in accordance with the data published by others ${ }^{7,10,14}$. Another general advantage of any PCR-based assay is its capability to detect invasive aspergillosis even if no viable fungal elements are present in the sample. By contrast, the presence of a sufficient amount of viable fungal elements is necessary if a cultivation method is to be successfully employed. Moreover, detection of viable fungal elements in the peripheral blood has been exceptional in the case of Aspergillus. For this reason, Aspergillus DNA detection in the peripheral blood by a PCR-assay should be preferred over cultivation techniques.

On the other hand, a number of practical problems are encountered in using molecular biology methods, e.g. false positivity resulting from contamination or false negativity resulting from presence of PCR-inhibitors, both of which can lead to an incorrect interpretation of the findings ${ }^{15}$. In addition, sensitivity of a PCR-assay can be decreased in patients receiving antifungal therapy ${ }^{16}$.

Material contamination can occur on several levels, and for this reason, the contamination risk should be minimized as much as possible. Firstly, contamination by air-borne conidia may occur during sampling. This risk is low in the case of blood samples, as an airtight sampling system is used. The risk, however, rises significantly in respiratory tract samples, sputum and endotracheal secretion in particular. It also cannot be excluded in the case of BAL, but it is substantially reduced. Hence, a single positive result is not conclusive for the diagnosis of invasive aspergillosis; two consecutive positive findings have much higher validity ${ }^{17-19}$.

Another source of contamination may come from laboratory processing, DNA extraction and preparation of reaction mixtures in particular. Negative controls as well as the amplification process may be contaminated, even though the latter occurs relatively rarely ${ }^{15}$. For this reason, we evaluated risk of contamination during DNA extraction using negative samples that were included in the set of the clinical samples. These negative controls were not found positive in any case. This clearly demonstrates high efficiency of the measures adopted to prevent cross-contamination of samples. In addition to strict adherence to general measures these relied also on the use dUTP and UNG (uracil-DNA-glycosylase).

Monitoring of the inhibition of the Taq DNA polymerase, which enables us to exclude falsely negative results, was also included in the assay. However, including an inhibition control into the reaction mixture itself is, in general, rather problematic, often leading to reduced sensitivity of the assay. This problem was resolved by running separate PCR assays targeting the housekeeping beta-globin gene, through which the presence of inhibitors was tested in all samples processed. This internal (inhibition) control must be positive in all samples, but we found 4 cases from 354 samples that were negative (confirmed presence of inhibitors).
A number of reports have shown that positive results for an PCR-assay found either repeatedly in consecutive samples from the same patient or correlating with a positive result of galactomannan (GM) detection from a sample processed in parallel correlated much better with clinical findings compared to single positive findings. Therefore, combined use of a PCR-assay and a GMassay has been demonstrated to significantly increase the chance of early and accurate IA diagnostics ${ }^{18,19}$. If a careful analysis of risk and predisposition factors is included together with the results of imaging methods (HR-CT), microbiological examination and detection of Aspergillus galactomannan and/or DNA, such a complex approach to patient can be of great help in early diagnostics and treatment of IA. Validation of an optimized PCR-assay is a key step to such an approach.

\section{ACKNOWLEDGEMENT}

Ministry of Health, Czech Republic, supported this work (grant no. NI/7498-3).

\section{REFERENCES}

1. Stevens DA, Kan VL, Judson MA, Morrison VA, Dummer S, Denning DW, Bennett JE, Walsh TJ, Patterson TF, Pankey GA. Practice guidelines for diseases caused by Aspergillus. Infectious Diseases Society of America. Clin Infect Dis 2000; 30:696-709.

2. von Eiff M, Roos N, Schulten R, Hesse M, Zuhlsdorf M, van de Loo J. Pulmonary aspergillosis: early diagnosis improves survival. Respiration 1995; 62:341-7.

3. Reichenberger F, Habicht JM, Gratwohl A, Tamm M. Diagnosis and treatment of invasive pulmonary aspergillosis in neutropenic patients. Eur Respir J 2002; 19:743-55.

4. Boucher HW, Groll AH, Chiou CC, Walsh TJ. Newer systemic antifungal agents: pharmacokinetics, safety and efficacy. Drugs 2004; 64:1997-2020.

5. Higashiyama Y, Kohno S. Micafungin: a therapeutic review. Expert Rev Anti Infect Ther 2004; 2:345-55.

6. Latgé JP. Aspergillus fumigatus and Aspergillosis. Clin Microbiol Rev 1999; 12:310-50.

7. Costa C, Costa JM, Desterke C, Botterel F, Cordonnier C, Bretagne S. Real-time PCR coupled with automated DNA extraction and detection of galactomannan antigen in serum by enzymelinked immunosorbent assay for diagnosis of invasive aspergillosis. J Clin Microbiol 2002; 40:2224-7.

8. Sidransky D, Tokino T, Hamilton SR, Kinzler KW, Levin B, Frost $\mathrm{P}$, Vogelstein B. Identification of ras oncogene mutations in the stool of patients with curable colorectal tumors. Science 1992; 256:102-5.

9. Bretagne S, Costa JM, Marmorat-Khuong A, Poron F, Cordonnier C, Vidaud M, Fleury-Feith J. (1995) Detection of Aspergillus species DNA in bronchoalveolar lavage by competitive PCR. J Clin Microbiol 1995; 33:1164-8.

10. Yamakami Y, Hashimoto A, Tokimatsu I, Nasu M. PCR detection of DNA specific for Aspergillus species in serum of patients with invasive aspergillosis. J Clin Microbiol 1996; 34:2464-8.

11. Yamakami Y, Hashimoto A, Yamagata E, Kamberi P, Karashima R, Nagai H, Nasu M. Evaluation of PCR detection of DNA specific for Aspergillus in sera of patients with various forms of pulmonary aspergillosis. J Clin Microbiol 1998; 36:3619-23.

12. Skladny H, Buchheidt D, Baust C, Krieg-Schneider F, Seifarth W, Leib-Mosch C, Hehlmann R. Specific detection of Aspergillus species in blood and bronchoalveolar lavage samples of immunocom- 
promised patients by two-step PCR. J Clin Microbiol 1999; 37: 3865-71.

13. Kami M, Ogawa S, Kanda Y, Tanaka Y, Machida U, Matsumura T, Sakamaki H, Hirai H. Early diagnosis of central nervous system aspergillosis using polymerase chain reaction, latex agglutination and enzyme-linked immunosorbent assay. Br J Haematol 1999; 106:536-7.

14. Costa C, Vidaud D, Olivi M, Bart-Delabesse E, Vidaud M, Bretagne S. Development of two real-time quantitative TaqMan PCR assays to detect circulating Aspergillus fumigatus DNA in serum. $\mathbf{J}$ Microbiol Methods 2001; 44:263-9.

15. Loeffler J, Hebart H, Bialek R, Hagmeyer L, Schmidt D, Serey FP, Hartmann M, Eucker J, Einsele H. Contaminations occurring in fungal PCR assays. J Clin Microbiol 1999; 37:1200-2.

16. Marr KA, Laverdiere M, Gugel A, Leisenring W. Antifungal therapy decreases sensitivity of the Aspergillus galactomannan enzyme immunoassay. Clin Infect Dis 2005; 40:1762-9.
17. Lass-Florl C, Aigner J, Gunsilius E, Petzer A, Nachbaur D, Gastl G, Einsele H, Loffler J, Dierich MP, Wurzner R. Screening for Aspergillus spp. using polymerase chain reaction of whole blood samples from patients with haematological malignancies. $\mathrm{Br} \mathbf{J}$ Haematol 2001; 113:180-4.

18. Buchheidt D, Hummel M, Schleiermacher D, Spiess B, Schwerdtfeger R, Cornely OA, Wilhelm S, Reuter S, Kern W, Sudhoff T, Morz H, Hehlmann R. Prospective clinical evaluation of a LightCycler-mediated polymerase chain reaction assay, a nestedPCR assay and a galactomannan enzyme-linked immunosorbent assay for detection of invasive aspergillosis. Br J Haematol 2004; 125:196-202.

19. Jordanides NE, Allan EK, McLintock LA, Copland M, Devaney M, Stewart K, Parker AN, Johnson PR, Holyoake TL, Jones BL. A prospective study of real-time panfungal PCR for the early diagnosis of invasive fungal infection in haemato-oncology patients. Bone Marrow Transplant 2005; 35:389-95. 